\title{
Editorial statement: The first five years of the European Journal of Government and Economics
}

Diego Varela, Universitatea Alexandru loan Cuza din lasi

Giacomo Benedetto, Royal Holloway, University of London

Jose Manuel Sanchez-Santos, Universidade da Coruña

\begin{abstract}
This editorial statement reflects on the experience from the first five years of the European Journal of Government and Economics and proposes some broad ideas about what we believe should be the future of the journal in the following years. The developments and ideas presented here are divided in three parts: achievements and difficulties of the past five-year period, the renewal of the editorial team, and new challenges for the future.
\end{abstract}

\section{Keywords}

Academic publishing; journal management.

\section{JEL classification}

A12; A30; P27. 
This editorial statement reflects on our experience as editors of the European Journal of Government and Economics during its first five years of existence. It also presents some broad ideas about what we believe should be the future of the journal in the following years. The exposition is divided in three parts: achievements and difficulties of the past five-year period, the renewal of the editorial team, and new challenges for the future of the journal.

\section{Achievements and difficulties}

The first five years of the European Journal of Government and Economics have been very intense ones in which we have made important achievements but also faced considerable difficulties.

As far as the achievements are concerned, besides managing to regularly publish two issues per year, which is an achievement in itself, we have also managed to include the journal in some globally recognised academic indices, such as a more stringent Directory of Open Access Journals, Econlit, Latindex and Scopus. Currently our journal is fully indexed by these services, which has increased its standing vis-à-vis fellow academics and authorities in a number of countries.

Achievements have also come on a personal side for the editors, and include the recent achievement of two Jean Monnet chairs selected by the European Commission to be co-funded by the Erasmus+ programme of the European Union, in European Political Economy and EU Budget Policy, respectively.

We have also faced difficulties, some of which still persist to a greater or lesser extent. One of these unresolved issues has been the understaffing of the journal, which has meant that the editors have had to undertake ourselves many of the tasks usually reserved for specialists, such as website management, copyediting or galley formatting of papers. This not only means an overload for the editors that detracts from their editorial duties, but also a gap in quality with respect to other journals.

A second difficulty that still persists is the lack of integration between the fields of government and economics. Although we are increasingly receiving a number of articles in areas that interlink both fields of politics and economics, the truth is that in many cases both fields have remained as watertight compartments. The increased level of technical sophistication of papers means that many experts in government do not understand or simply are not interested in the papers in the field of economics, and vice versa.

Another issue is related to the vocation of the journal to expand to other countries, and in particular to contribute to the integration of former communist countries of Eastern Europe. The difficulty in this case comes from the lack of economic and social cohesion in Europe, which translates into great differences as far as research quality is concerned. In practical terms, this means that the distance between authors and reviewers across regions is so great that it is rather difficult to find an able reviewer or to get a paper accepted, unless regions are kept segregated, which is the opposite to our initial intentions as editors.

But all in all the balance is positive, the main benefit being the experience we have acquired through the management of the journal, the contacts we have made, and the cohesion we have developed among the members of the editorial team.

\section{Renewal of the editorial team}

These initial five years would not be possible without the help of our editorial board, which has brought together more than 30 colleagues from a number of countries in Europe and beyond. After five years of service, time has come to thank them expressly for their efforts. Besides us, this editorial board has included the following members: 
- Manel Antelo, Universidad de Santiago de Compostela, Spain

- Eduardo Bandres, Universidad de Zaragoza, Spain

- Michael W. Bauer, Humboldt University Berlin, Germany

- Peter Benczur, European Commission, Joint Research Centre, Ispra, Italy

- Oscar Calvo-Gonzalez, World Bank, Washington DC, United States

- Jose Ramon Cancelo, Universidade da Coruña, Spain

- Raul Caruso, Università Cattolica del Sacro Cuore, Milano, Italy

- Luiz de Mello, Organisation for Economic Co-operation and Development, France

- Michael Ehrmann, European Central Bank, Frankfurt, Germany

- Fabio Franchino, Università degli studi di Milano, Italy

- Miriam Hartlapp, Wissenschaftszentrum Berlin für Sozialforschung, Germany

- Bjorn Hoyland, University of Oslo, Norway

- Raya Kardasheva, Kings College London, United Kingdom

- Santiago Lago-Peñas, Universidad de Vigo, Spain

- Thierry Madies, Université de Fribourg, Switzerland

- Diego Martinez-Lopez, Universidad Pablo de Olavide, Sevilla, Spain

- Jorge Martinez-Vazquez, Georgia State University, United States

- Jan-Hinrik Meyer-Sahling, University of Nottingham, United Kingdom

- Carmen Nastase, Universitatea Stefan cel Mare din Suceava, Romania.

- Jorge Onrubia, Universidad Complutense de Madrid, Spain

- Fabio Padovano, Università degli Studi Roma Tre, Italy

- Antti Pajala, University of Turku, Finland

- George Poede, Universitatea Alexandru Ioan Cuza din lasi, Romania

- Lucia Quaglia, University of York, United Kingdom

- Yvon Rocaboy, Université de Rennes 1, France

- Andres Rodriguez-Pose, London School of Economics and Political Science, United Kingdom

- Fritz Sager, Universität Bern, Switzerland

- Roger Scully, Cardiff University, United Kingdom

- Stephan Stetter, Universität der Bundeswehr München, Germany

- Virgil Stoica, Universitatea Alexandru Ioan Cuza din lasi, Romania

- Robert Thomson, University of Strathclyde, United Kingdom

- Frantisek Turnovec, Univerzita Karlova v Praze, Czech Republic

- Richard C. Whitaker, University of Leicester, United Kingdom

After five years, a new cycle starts that will surely bring a renewed editorial team with new faces both among editors and editorial board members, a team that will be able to base its project on the work initiated by these colleagues to whom we hereby thank, but that will also bring new ideas and enthusiasm with them.

\section{New challenges for the future}

The challenges for the new editorial team are related to the difficulties that we have mentioned above, the first of which will be, in our opinion, the needed professionalization of the journal. Assuring the specialisation of functions such as copyediting, proofreading or formatting will allow editors to focus on their own functions and increase the quality of the journal. It is an open question whether this can be better undertaken at home or by means of outsourcing, and whether the 
funding for such improvements may come from subscription fees, author publishing fees, or some kind of institutional sponsorship.

Other unresolved issues that have been mentioned above are the integration of the fields of government and economics, and the integration of academics from different regions of the world with different academic backgrounds.

Finally, and most importantly, the new editorial team will need to continue our efforts to increase the quality of published papers. This, in turn, will allow the journal to rise in citation rankings and, ultimately, to be admitted to additional indices such as the Journal of Citation Reports, and further increase in recognition and influence (Varela, 2013).

All these challenges are difficult ones in themselves, but especially if we consider that they interact among them. For instance, rising in established citation rankings may conflict with the objective to open up the journal to new countries and regions. Institutional sponsorship arrangements needed for the professionalisation of the journal may also conflict with the journal's autonomy. All in all, these are just a few of the open questions that will make the next cycle a challenging one for the editorial team of the European Journal of Government and Economics.

\section{References}

Varela, Diego (2013) 'The contribution of ISI indexing to a paper's citations: Results of a natural experiment', European Political Science 12(2): 245-53. 